\title{
RUANG PERANTARA MANUSIA DENGAN HEWAN
}

\author{
Jennifer Chandra ${ }^{1)}$, Sidhi Wiguna Teh ${ }^{2)}$ \\ 1)Program Studi S1 Arsitektur, Fakultas Teknik, Universitas Tarumanagara,jenniferchandra@outlook.com \\ 2) Program Studi S1 Arsitektur, Fakultas Teknik, Universitas Tarumanagara, sidhi@ft.untar.ac.id
}

\begin{abstract}
Abstrak
Milenial sedang menghadapi krisis psikososial ke-6 yang berkaitan dengan hubungan relasi dengan pihak-pihak lain. Keberhasilan dalam melewati tahap ini akan membentuk sebuah individu yang mengenal cinta dan bahagia, kegagalan dalam melewati tahap ini adalah isolasi yang dapat menjurus kearah masalah mental seperti depresi. Terapi hewan telah dibuktikan dapat membantu untuk memperbaiki hubungan manusia dan juga memberikan dampak yang sangat baik pada sifat dari hubungan tersebut. Sebuah wadah dibutuhkan untuk mewadahi kegiatan tersebut. Artikel ilmiah ini akan membahas mengenai perancangan sebagai wadah kegiatan. Pembahasan akan meliputi analisis dan sintesis dari data-data yang telah dikumpulkan, dan output perancangan.
\end{abstract}

Kata kunci: Hewan Peliharaan; Hubungan; Milenial; Terapi Hewan

\begin{abstract}
Millennials are currently facing the $6^{\text {th }}$ stage of Psychosocial Crisis which revolves around the nature of relationships. Success in going through this phase will lead them to love and intimacy, while failure will result in isolation and in some cases might lead to depression and other mental health problems. Animal Assisted Therapy has been proven to be effective in the correction of an individual's relationship orientiation. A space is needed to accommodate these programs and activities in which humans and animals are concerned. This journal will be discussing the design of the previously mentioned required space. Discussion will include analysis and syntesis of the datas collected, and also the final design output.
\end{abstract}

Keywords: Animal Assisted Therapy; Millennials; Petting Zoo; Relationships; Companion Animals

\section{PENDAHULUAN}

Kaum milenial pada saat ini sedang memasuki tahap di dalam siklus kehidupan, dimana mereka sedang mencoba untuk mencari tempat untuk mereka sendiri di dunia ini. Mereka memulai untuk mencari pasangan hidup, memperluas lingkaran pertemanan mereka dan bertemu dengan orang orang baru yang bukanlah keluarga atau kerabat dekat mereka. Hubungan-hubungan yang mereka jalin dapat bersifat sehat dan tidak sehat. Hubungan tersebut akan memiliki dampak yang besar pada kesehatan hubungan mereka dan kesehatan mental mereka. Animal Assisted Therapy telah dibuktikan sebagai salah satu cara yang efektif untuk membantu mengatasi konflik tersebut.

Data-data literatur mengenai hubungan, keterikatan dan terapi intervensi hewan akan dilampirkan di bawah ini. Data-data yang telah didapat akan kemudian dianalisis sehingga muncul sebuah program arsitektural. Program tersebut akan melahirkan arsitektur yang berfungsi sebagai wadah untuk program dan kegiatan pemulihan hubungan milenial dan kesehatan mental mereka. 


\section{KAJIAN LITERATUR}

\section{Generasi Milenial}

Millennials lahir dari tahun 1980 hingga 1995 (Foot dan Stoffman, 1998). Millennials adalah anak-anak dari kaum baby boomers (1946-65). Lingkungan dimana millennials bertumbuh besar memiliki dampak terhadap nilai-nilai, sikap dan perilaku mereka. Millennials sangat terpengaruh dari tren yang berdampak besar terhadap mereka seperti bertambahnya jumlah tenaga kerja wanita, meningkatnya perceraian dan perkembangan teknologi yang pesat (Lancaster dan Stillman, 2009).

\section{Teori Life Cycle}

Dalam buku yang berjudul The Human Odyssey: Navigating the Twelve Stages of Life yang ditulis oleh Thomas Armstrong PhD, dikatakan bahwa setiap tahapan dalam kehidupan manusia sangat penting dan sangat dibutuhkan untuk kesejahteraan manusia. Setiap tahap pada kehidupan memiliki keunikan masing masing dan berperan sebagai sebuah karunia yang berkontribusi pada dunia. Untuk mendukung kebutuhan hidup dalam kehidupan manusia yang terdalamn, maka setiap karunia tersebut harus dihargai. Ke 12 tahapan kehidupan adalah sebagai berikut:
a. Prebirth: Potential
b. Birth: Hope
c. Infancy (0-3 tahun): Vitality
d. Early Childhood (3-6 tahun): Playfulness
e. Middle Childhood (6-8 tahun): Imagination
f. Late Childhood (9-11 tahun): Ingenuity
g. Adolescence (12-20 tahun): Passion
h. Early Adulthood (20-35 tahun): Enterprise
i. Midlife (35-50 tahun): Contemplation
j. Mature Adulthood (50-80 tahun): Benevolence
k. Late Adulthood (80 tahun keatas): Wisdom
I. Death \& Dying: Life

Generasi millennial yang berumur 23- 38 tahun di tahun 2019, sedang berada di tahap ke 8 yaitu tahap Early Adulthood dan persentase kecil dari mereka sedang memasuki awal tahap ke 9 yaitu Midlife. Tahap ke-8 adalah sebuah tahap dimana manusia sedang mencoba untuk mewujudkan tanggung jawab mereka, contohnya seperti untuk membangun keluarga dan mencari pasangan hidup. Tahap ke-9 adalah sebuah tahap dimana mereka cenderung memilih untuk beristirahat dan merenungi arti dari kehidupan masing-masing individu.

\section{Psychosocial Theory}

Menurut teori dari Erik Erikson, manusia akan mengalami atau melewati 8 tahap kehidupan. Di setiap tahap, manusia akan menghadapi kesulitan dan tantangan-tantangan yang ada dalam hidup. Berikut adalah ke delapan tahapan dalam kehidupan.

\section{Perkiraan Usia}
a. Bayi - 18 bulan
b. 18 bulan -3 tahun
c. $3-5$ tahun
d. $5-13$ tahun
e. 13-21 tahun
f. 21-39 tahun
g. 40-65 tahun
h. 65 tahun keatas

Krisis Psycho Social

Trust vs. Mistrust

Autonomy vs. Shame and Guilt

Initiative vs. Guilt

Industry vs. Inferiority

Identity vs. Role Confusion

Intimacy vs. Isolation

Generativity vs. Stagnation

Ego Integrity vs. Despair 
Kaum yang menjadi prioritas pada proyek ini adalah kaum millennial yang pada saat ini sedang berada di tahap ke 6 yaitu tahap krisis Psychosocial Intimacy vs. Isolation. Manusia yang sedang berada di tahap ini sedang mengalami tantangan hidup mengenai hubungan. Pada tahap ini, mereka sedang mencoba untuk menjalin hubungan dengan orang selain orang tua dan kerabat dekat mereka. Mereka mulai untuk membagi kehidupan mereka dengan orang lain, dan mengeksplorasi hubungan-hubungan yang akan menjurus ke komitmen jangka panjang.

Kesuksesan dalam tahap ini akan menghasilkan orang yang mengerti cinta, dapat berkomitmen dan berada dalam hubungan yang nyaman. Kegagalan dalam tahap ini biasa nya akan mengakibatkan seseorang menjadi kesepian, terisolasi dan bahkan menjadi depresi.

\section{Adult Attachment Theory}

Salah satu dari sejumlah faktor yang dapat mempengaruhi kesehatan sebuah hubungan adalah Attachment Orientation. Adult Attachment Theory (Bowlby, 1982, 1988; Hazan \& Shaver, 1987; Mikulincer \& Shaver, 2003, 2007) digunakan dalam studi hubungan antara manusia, studi hubungan manusia dengan manusia dan hubungan antara kedua hubungan tersebut. Attachment Orientation atau orientasi keterikatan adalah sebuah pola sistematik dari ekspektasi yang relasional, emosi dan perilaku yang diakibatkan oleh sebuah riwayat keterikatan (Fraley \& Shaver, 2000).

Riset dari Ainsworth et al. pada tahun 1978 dan studi mengenai tingkah laku dan psikologi sosial mengatakan bahwa attachment orientation dapat diukur dengan attachment anxiety dan attachment avoidance, yang merupakan dua dimensi yang orthogonal (Brennan, Clark, \& Shaver, 1998). Attachment anxiety adalah sebuah dimensi yang mengindikasi tingkat dimana manusia khawatir jika seorang pasangan tidak akan ada untuknya di saat ia membutuhkan mereka, dan selalu bertekad untuk memiliki 'kedekatan' yang sangat dekat dengan pasangan mereka. Attachment avoidance adalah sebuah dimensi yang mengindikasi tingkat kepercayaan seseorang terhadap pasangan mereka dan selalu mencoba untuk bergantung kepada diri sendiri daripada orang lain. Setiap individual memiliki tingkat attachment anxiety dan attachment avoidance yang berbeda-beda, dan hal tersebut mencerminkan attachment security dan cara orang tersebut menghadapi stress(Mikulincer \& Shaver, 2003, 2007).

\section{Human-Pet dan Human-Human Relationships}

Hewan peliharaan seperti anjing dan kucing telah melewati transformasi radikal pada kehidupan masyarakat, dari yang berawal sebagai sumber makanan dan bantuan dalam pekerjaan manusia hingga pada saat ini hewan sebagai bagian intergral dalam sebuah unit kelurga manusia. Banyak studi yang mengatakan bahwa kepemilikan hewan peliharaan dapat meningkatkan kesehatan fisik dan mental manusia. Karena hewan memiliki efek positif bagi manusia, maka hewan peliharaan mulai direkrut menjadi hewan terapi yang akan membantu berkontribusi pada kualitas hidup manusia.

Attachment bonds dengan hewan dapat diwujudkan karena hewan adalah obyek attachment yang natural, mereka selalu ada disaat kita membutuhkan, aktif, lincah dan penyayang (Levinson, 1969). Pemilik hewan menganggap hewan peliharaan sebagai tempat berlindung mereka yang selalu bersedia untuk memberikan majikannya kasih, cinta, dukungan dan ketenangan di saat mereka membutuhkannya (e.g., Allen, Balscovich, \& Mendes, 2002; Geisler, 2004; Kurdek, 2008; Odendaal \& Meintjes, 2003). Hubungan antar manusia dan hubungan manusia dengan hewan peliharaan telah terbukti dari riset bahwa kedua hubungan tersebut berkaitan. Attachment anxiety dan attachment avoidant dalam hubungan manusia dengan hewan bersifat orthogonal.

Menurut riset, attachment insecurities (attachment anxiety dan avoidance) dalam hubungan antar manusia dapat dikaitkan secara positif pada attachment insecurities (attachment anxiety dan avoidance) dalam hubungan antara manusia dan hewan. Terapi untuk menyehatkan kembali attachment orientation manusia dilakukan dengan cara mengubah 
tingkat attachment anxiety dan attachment avoidant dalam hubungan manusia tersebut dengan hewan. Tingkat anxiety dan avoidant manusia nantinya akan berubah dan kondisi hubungan menjadi lebih sehat setelah menjalani terapi dengan hewan. Karena attachment insecurities dalam hubungannya dengan hewan berubah menjadi attachment securities, maka menurut hasil dari riset dan studi, hubungannya dengan manusia lain juga akan berubah dan menjadi lebih positive dan secure. Dengan menjalin hubungan yang positif dan membangun, kesehatan mental dari setiap individu pun akan membaik dan menjadi lebih sehat secara mental dan juga fisik.

\section{Animal Welfare}

Menurut Department of Primary Industries dan Royal Society for the Prevention of Cruelty to Animals (RSPCA) yang telah didirikan sejak 1824, beberapa faktor dalam menjaga kesehatan hewan peliharaan secara fisik dan mental adalah:

Tabel 1. Tabel Kebutuhan dan Kebiasaan Anjing

\begin{tabular}{l}
\hline Anjing \\
\hline Anjing harus tinggal di area yang nyaman, kering, bersih dan tenang \\
\hline Menyediakan tempat kamar kecil karena anjing membuang air kecil setiap beberapa jam \\
\hline Menyediakan area untuk berohlaraga, dimana para anjing dapat bersosialisasi \\
\hline Sebuah area yang tidak akan membosankan anjing karena mereka cepat bosan \\
\hline Sebuah tempat berlindung bagi masing-masing \\
\hline Sediakan tempat tidur, mainan dan tempat persembunyian jika terdapat banyak anjing \\
\hline Ukuran dan temparatur harus cocok untuk para anjing \\
\hline Memagari tempat bermain mereka untuk mencegah anjing yang keluar dan tersesat \\
\hline Sumber: Olahan dari berbagai sumber, 2019 \\
\hline Bubel 2. Tabel Kebutuhan dan Kebiasaan Burung \\
\hline Suhu dan temperatur harus disesuaikan dengan burung \\
\hline Sangkar tidak boleh berpotensi untuk melukai burung \\
\hline Menjaga kebersihan \\
\hline Memastikan tidak akan ada sela dimana burung-burung dapat kabur \\
\hline Menyediakan tempat untuk dihinggapi para burung \\
\hline Tidak merekomendasikan keberadaan cermin
\end{tabular}

Sumber: Olahan dari berbagai sumber, 2019 
Tabel 3. Tabel Kebutuhan dan Kebiasaan Kelinci

\begin{tabular}{l}
\hline Kelinci \\
\hline Kelinci sangat aktif, membutuh ruang untuk lari, loncat, gali dan berdiri dan tiduran \\
prenyediakan ruang yang besar dan aman untuk istirahat dan perlindungan dari \\
\hline Kelinci adalah hewan yang biasanya sering dimangsa sehingga mereka butuh tempat \\
untuk bersembunyi \\
\hline Kelinci harus berohlaraga setiap hari untuk mencegah kebosanan yang dapat \\
mengakibatkan ketidaksehataan \\
\hline Mereka butuh tempat tidur yang hangat dan aman untuk dimakan \\
\hline Temperatur harus sesuai dengan kebutuhan kelinci \\
\hline Area toilet harus dipisah dari area tidur \\
\hline Kelinci mudah terluka maka tempat tinggal mereka harus aman dan nyaman. \\
\hline Sumber: Olahan dari berbagai sumber, 2019 \\
\hline Kuda \\
\hline Tempat tinggal kuda harus aman dan tidak berbahaya \\
\hline Tempat harus dipagari sehingga tidak akan ada kuda yang bisa keluar \\
\hline Kuda harus memiliki akses ke lahan hijau, dimana mereka bisa bersosialisasi \\
\hline Menyediakan tempat teduh dari terik matahari atau cuaca dan temperatur yang ekstrim \\
\hline Memiliki area kering untuk berdiri dan tiduran \\
\hline Memastikan bahwa area kuda memiliki ventilasi yang baik dan bersih \\
\hline Memastikan tempat tidur bersih untuk menjaga kesehatan kuda \\
\hline Merencanakan rencana apabila terjadi bencana atau kebakaran \\
\hline Pastikan tempat tinggal kuda sesuai dengan ukuran yang dibutuhkan \\
\hline Pekarangan yang memiliki minimal 3m lebarnya dan luas minimal $20-35$ m2 \\
\hline Kanopi atau atap memiliki ketinggial minimal $3.7 \mathrm{~m}$ \\
\hline Kandang kuda berdimensi sekurang-kurangnya $3.7 \times 3.7 \mathrm{~m}, 3.7 \times 4.9 \mathrm{~m}$ disarankan. \\
\hline Dinding memiliki ketinggian setidaknya $1.2 \mathrm{~m}$ \\
\hline Sumber: Olahan dari berbagai sumber, 2019 \\
\hline
\end{tabular}

Tabel 5. Tabel Kebutuhan dan Kebiasaan Kucing

\begin{tabular}{l}
\hline Kucing \\
\hline Tempat yang kering, bersih dan tenang untuk kucing beristirahat \\
\hline Akses mudah untuk ke toilet \\
\hline Tempat makan, toilet dan tempat tidur harus dipisah \\
\hline Siapkan tempat persembunyian untuk para kucing saat mereka sedang takut \\
\hline Sediakan beberapa tempat yang berbeda-beda agar kucing tidak cepat bosan \\
\hline Ruang untuk kucing meloncat, berlari dan memanjat \\
\hline Karena kucing cenderung merasa aman di ketinggian, mereka suka memanjat dan \\
berada di tempat yang tinggi \\
\hline Temperatur dan suhu udara harus sesuai dengan kebutuhan \\
Sumber: Olahan dari berbagai sumber, 2019
\end{tabular}


Menurut Dr. Rob Marshall, B. V. Sc, M.A.V. C. Sc., burung-burung seperti cockatiels dan parrots, memiliki sifat dan kebutuhan sebagai berikut:

Tabel 6. Tabel Kebutuhan dan Kebiasaan Burung

\begin{tabular}{l}
\hline Burung \\
\hline Tidur di area atau ruangan yang gelap \\
\hline Membutuhkan sinar matahari khusus nya untuk mendapatkan vitamin D3 dari sinar \\
matahari \\
\hline Sangat sensitif terhadap angin yang kencang (strong wind) \\
\hline Merupakan hewan yang biasa diburu (prey animals) \\
\hline Memiliki naluri untuk berburu makanan di alam liar. Naluri ini yang akan membantu \\
untuk nurture their skills and intelligence, and will result in retardation if this foraging \\
skill is not developed well
\end{tabular}

Sumber: Olahan dari berbagai sumber, 2019

\section{Spatial Agency}

Dalam buku Spatial Agency: Other Ways of Doing Architecture, Spatial Agency meredefinisi apa itu arsitektur dan apa gunanya. la merepresentasikan kemungkinan untuk praktek di masa depan yang berbasis prinsip melibatkan etik dan kolaborasi. la juga merepresentasikan kelompok yang terlibat dan sedang terlibat dalam kalibrasi ulang nilai profesional dan kekhawatiran socio-spatial pada bidang tersebut. la mengusulkan cara lain untuk melakukan arsitektur. Special Agency bermula dari sebuah proyek yang berfokus pada user dan orang lain, memprioritaskan mereka sebelum praktek arsitektur. Spatial Agency menyebarkan potensi dan pengetahuan mengenai proses arsitektural untuk memberi kekuasaan dan kekuatan bagi user agar mereka dapat mengontrol ruang yang mereka huni.

\section{Ruang dan Fengshui}

Kolom dan balok pada suatu ruangan sangat berpengeruh terhadap pengalaman apabila seseorang sedang berada di dalam ruangan tersebut. Fengshui dapat membantu user pada suatu ruangan untuk mendapatkan keuntungan yang sangat optimal, dimana ruangan tidak hanya terlihat indah dan nyaman, tetapi membantu user ruangan untuk merasakan performa kehidupan yang maksimal (Yap, 2004).

Solusi arsitektur untuk memberikan energi yang positif bagi suatu ruangan adalah dengan cara memberikan plafon untuk menutup balok, menghilangkan siku-siku pada kolom dan disarankan untuk tidak duduk berhadapan dengan kolom (Teh, Lianto, \& Trisno, 2018).

\section{METODE}

Data-data yang akan dikumpulkan adalah data tapak seperti kondisi, peraturan, transportasi, aksebilitas, polusi, orientasi, masalah dan lain-lainnya yang dapat mempengaruhi proses perancangan dan pemilihan tapak. Setelah menemukan alternatif tapak, maka akan dilakukan skoring tapak untuk memilih tapak yang paling berpotensi dan cocok untuk program yang sudah dipilih. Apabila tapak sudah dipilih, maka akan dilakukan analisis yang lebih mendalam terhadap tapak tersebut.

Metode Perancangan yang digunakan adalah metode metafora. Bangunan ini memiliki tujuan untuk mendekatkan hewan peliharaan dengan manusia yang hasilnya akan dapat menguntungkan kedua pihak. Hewan peliharaan dapat membantu memperbaiki dan memberikan dampak positif bagi manusia secara mental, membantu agar hubungan yang terjalin sehat. Hewan yang berada di dalam bangunan akan difokuskan untuk hewan-hewan yang berkeliaran di jalanan dan hewan-hewan yang di-abuse. Hewan-hewan tersebut lalu akan di-rescue dan diberikan sebuah kesempatan hidup di sebuah lingkungan yang layak di mana mereka mendapatkan kasih sayang dan perhatian yang mereka deserve. Metode metafora diterapkan pada fasad dan ruangan dan suasana di dalam bangunan tersebut. Secara visual, 
maka bangunan ini akan terlihat seperti sebuah 'kandang' atau 'penjara' yang merepresentasikan kondisi hati setiap manusia yang sedang berada di dalam hubungan yang tidak sehat atau kondisi mental yang kurang sehat. Mereka merasa terperangkap dan tidak dapat dengan leluasa mengekspresikan diri mereka sendiri. Dari sisi hewan peliharaan yang hidup di tengah-tengah perkotaan, dimana manusia lah yang memiliki kekuatan terbesar, hewan-hewan peliharaan biasa diasosiasikan dengan kandang, tempat tinggal yang diciptakan manusia untuk para hewan. Kedua user bangunan yang seolah-olah berada di dalam 'kandang' akan mendapatkan sebuah pengalaman ruang yang terapeutik dan menyembuhkan melalui terapi yang dilaksanakan di dalam bangunan. Ruang yang berada di dalam bangunan dirancang agar memberikan suasana yang kontras dengan apa yang terlihat dari luar. Ruang di dalam bangunan tidak memiliki batas yang keras antara hewan dengan manusia, sebuah tempat dimana manusia dan hewan dapat hidup berdampingan. Hewan dan manusia akan mendapatkan keadilan dan perlakuan yang sama tanpa diskriminasi. Suasana di dalam juga akan memberikan nuansa yang terapeutik dan tenang. Alam akan diintegrasikan kedalam bangunan untuk membantu kefektivitasan terapi.

\section{DISKUSI DAN HASIL}

Arsitektur yang menjadi jawaban dari persoalan dan isu psychosocial crisis adalah sebuah wadah untuk mengakomodasikan kegiatan penyembuhan dan pemulihan kesehatan mental, ketidaksehatan yang merupakan dampak dari kegagalan dalam hubungan antar manusia. Bangunan yang dirancang memiliki fungsi utama yaitu sebagai sebuah Therapeutic Center yang mempraktekan terapi hewan atau Animal-Assisted Therapy. Hewan terapi dapat membantu menurunkan tingkat ketidaksehatan mental seseorang dengan cara berinteraksi dengan manusia.

User wadah ini tidak hanya sebatas pasien, terapis dan hewan terapi. Seluruh masyarakat tanpa terkecuali, dapat mengunjungi dan menghabiskan waktu di wadah tersebut. Publik pada umumnya tidak akan mendatangi dan menghabiskan waktu luang atau hangout di sebuah tempat yang bernama dan dikenal sebagai tempat terapi. Untuk menarik perhatian publik untuk datang, maka sebuah 'false front' digunakan pada bangunan. Publik akan memiliki persepsi yang salah bahwa tempat tersebut adalah tempat rekreasi dan entertainment yang bertema hewan peliharaan, namun sebetulnya bangunan tersebut mempunyai motif tersembunyi yaitu sebagai tempat pemulihan ketidaksehatan mental dan emosi. Dengan menipu dan menciptakan persepsi yang salah agar publik mengira bahwa bangunan tersebut adalah tempat rekreasi, publik akan lebih tertarik untuk datang berkunjung. Publik yang datang dan berinteraksi dengan hewan terapi akan tanpa ia sadari sedang menjalani terapi dengan hewan tersebut.

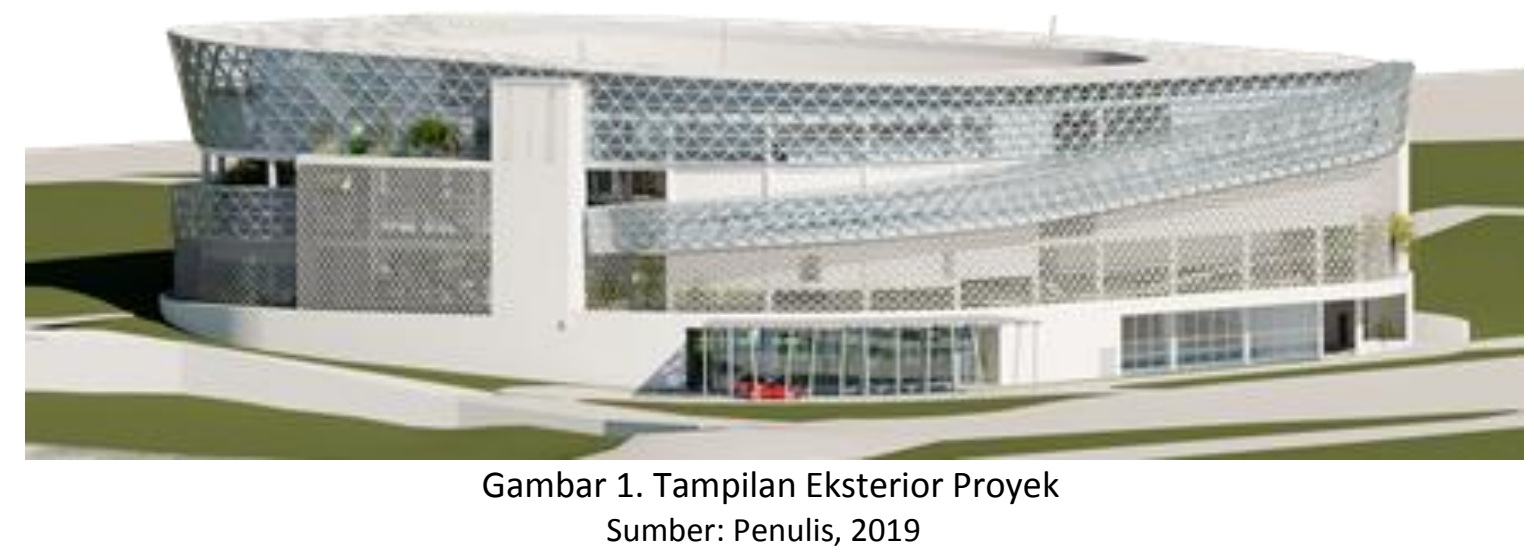

Karya arsitektur yang dilahirkan berjudul Mediate Space: Connecting Man and Pet(s) atau Ruang Perantara Manusia dengan Hewan. Bangunan ini terletak di Jagakarsa, Jakarta Selatan, 
lebih tepatnya di JI. TB. Simatupang. Proyek tersebut berada di atas lahan sebesar $8333 \mathrm{~m}^{2}$ dan memiliki luas bangunan sebesar $8000 \mathrm{~m}^{2}$.
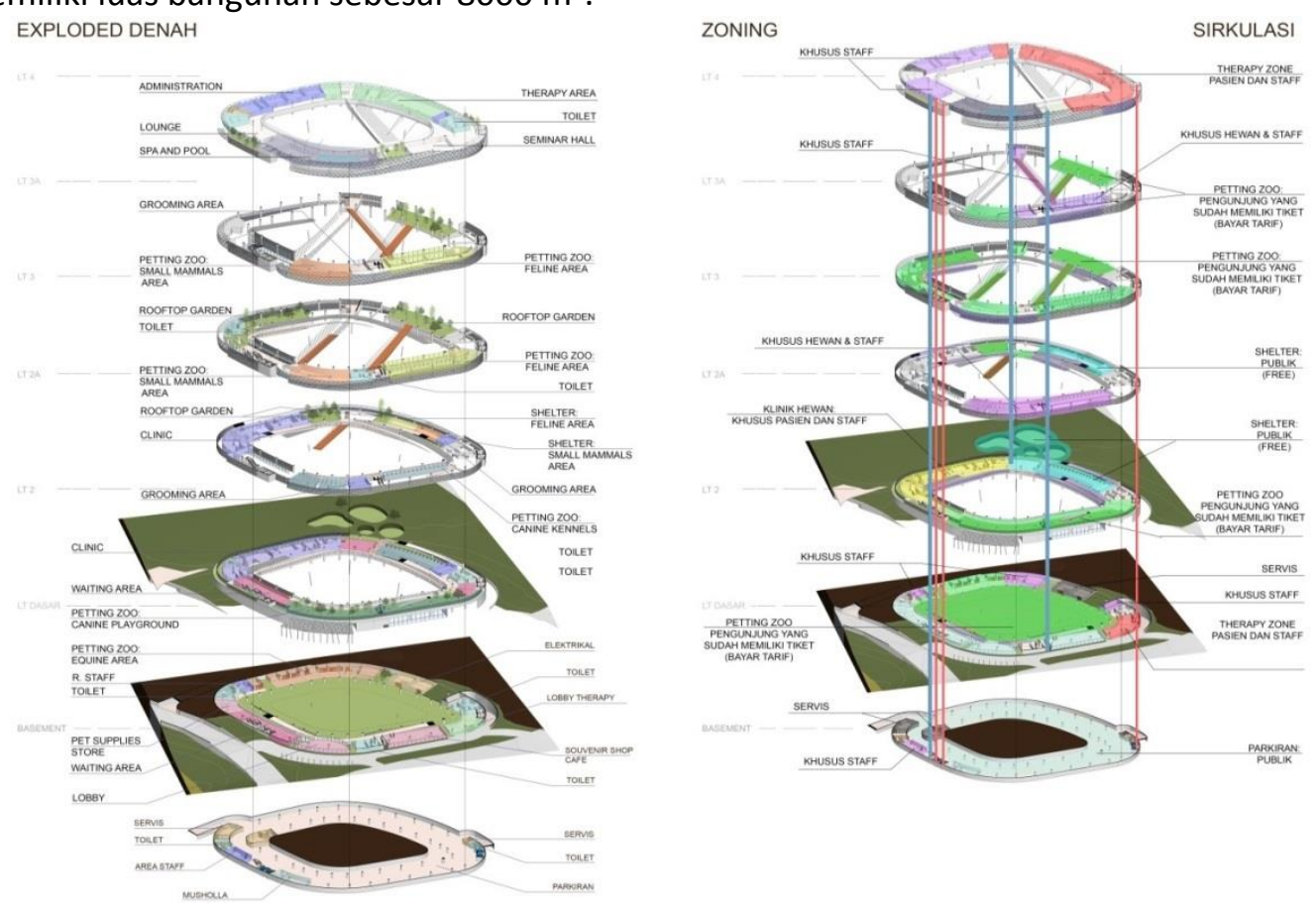

Gambar 2. Denah Exploded, Zoning, dan Sirkulasi.

Sumber: Penulis, 2019

Pembagian program bangunan dilakukan secara vertikal maupun horizontal dengan memperhatikan kenyamanan dan efisiensi bagi pengguna. Adanya ruang-ruang transisi antar program untuk membuat program saling terhubung namun masih memiliki area program yang jelas.

Arsitektur yang dilahirkan berjudul Mediate Space: Connecting Man and Pet(s) atau Ruang Perantara Manusia dengan Hewan. Bangunan ini terletak di Jagakarsa, Jakarta Selatan, lebih tepatnya di J. TB. Simatupang. Proyek tersebut berada di atas lahan sebesar $8333 \mathrm{~m} 2$ dan memiliki luas bangunan sebesar $8000 \mathrm{~m}^{2}$.

Program bangunan therapeutic center berfokus pada kegiatan interaksi antara hewan dengan manusia. Kegiatan terapi dengan hewan dibagi menjadi dua: Area Animal Assisted Therapy yang berfungsi sebagai fasilitas kesehatan mental dan Area Petting Zoo yang berfungsi sebagai tempat rekreasi terapeutik.
a. Therapy Ward
Terapi hewan dengan terapis profesional, ruang terapi berbeda-beda dan disesuaikan dengan kondisi pasien. Dalam program ini pasien datang dengan niat untuk berkonsultasi layaknya klinik terapi lainnya, prosedur yang dijalankan juga sama dengan klinik atau rumah sakit. Ruangan terapi berbeda-beda dari ruang privat untuk terapi individual hingga ruang terapi secara berkelompok.
b. Communal Spaces, Play Areas, Petting Zoo
Terapi hewan yang dijalani hanya dengan berinteraksi dengan hewan terapi. Di program ini, publik akan berkunjung untuk bermain dan berinteraksi dengan hewan terapi tanpa pengawasan dan kehadiran terapis profesional. Kegiatan ini berlangsung di sebuah communal space, dimana akan terjadi interaksi antar manusia juga.
c. Souvenir Shop, Cafes, Lounges 
Tersedia cafe, lounge, souvenir shop dan tempat bersantai lainnya yang pada saat ini merupakan lokasi-lokasi hits dimana para kaum millennial gemar untuk berkumpul dan hangout.

d. Observatory Area

Bagi para pengunjung yang masih tidak terlalu berani untuk berada di dekat hewan-hewan, terdapat area yang bebas dari hewan. Dari area observasi ini, pengunjung dapat melihat dan mendengar kegiatan yang sedang belangsung di communal spaces dan play areas, tanpa harus berinteraksi langsung dengan hewan-hewan.

e. Animal Care

Untuk menjaga kesehatan fisik dan mental para hewan terapi, terdapat area khusus untuk perawatan hewan, seperti klinik dan grooming center.

f. Area Staff

Area khusus staff yang bekerja di tempat tersebut. Terdiri dari ruang karyawan, pantry, loker, dan lainnya.

g. Entrance/Area Penerima

Ruang yang menyambut para pengunjung berupa lobby, lounge, resepsionis dengan kamar mandi tamu. Area parkir kendaraan bermotor milik pengunjung dan karyawan.

h. Service

Area service penunjang bangunan terdiri dari area MEP, ruang genset, ruang sekuriti dan lain-lain.

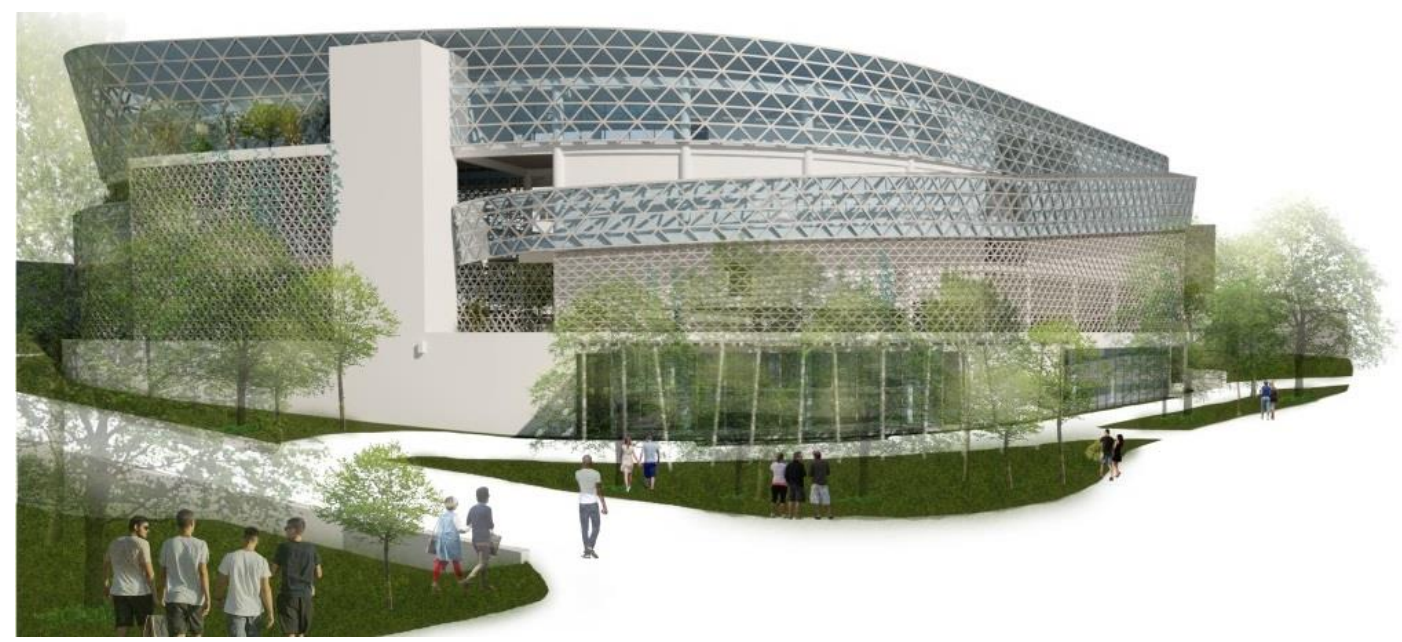

Gambar 3. Suasana Eksterior Bangunan

Sumber: Penulis, 2019

Fasad bangunan yang memberikan kesan seperti kandang dan kurungan diwujudkan dengan menggunakan struktur eksoskeleton yang juga dipadu dengan breeze block beton yang bermotif silang. Ruang-ruang di dalam bangunan yang menyeimbangkan kepedulian terhadap manusia dan hewan dapat diwujudkan dengan mengurangi barrier antara manusia dengan hewan dan juga menjaga privacy masing-masing individu baik manusia maupun hewan "to $a$ certain extent". 


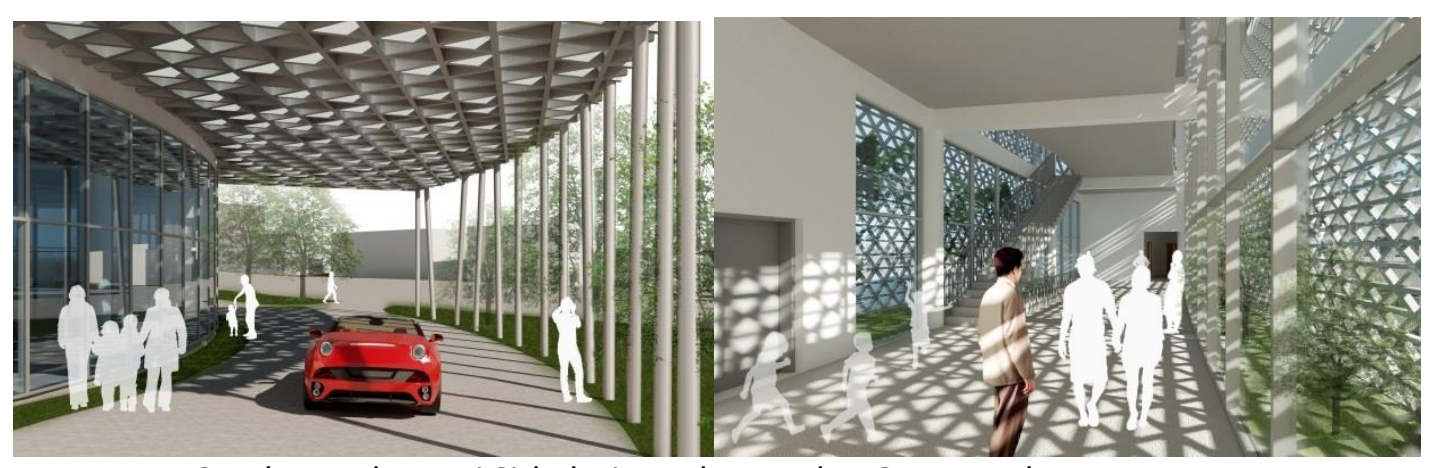

Gambar 4. Ilustrasi Sirkulasi Kendaraan dan Orang Pada Bangunan Sumber: Penulis, 2019

Gambar 4 dan Gambar 5 menunjukan usaha perancang untuk menyatukan alam dengan bangunan. Hal ini dapat dilihat dari bayangan-bayangan yang meniru bayangan dari pepohonan. Tiang-tiang yang tidak berdiri tegak lurus melainkan tidak beraturan memberikan kesan seperti batang batang pepohonan. Elemen-elemen tersebut tentu juga membantu dalam faktor estetika.

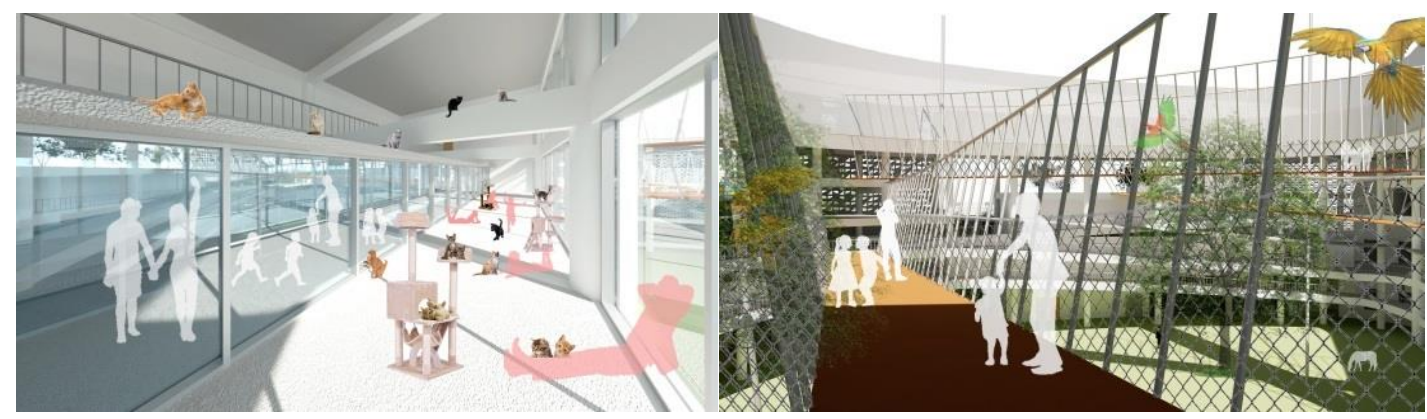

Gambar 5. Ilustrasi Ruang-Ruang Dalam Pada Bangunan Sumber: Penulis, 2019

Material yang digunakan pada bangunan sederhana dan low maintenance. Detail penghijauan atau alam juga diintegrasikan ke dalam bangunan dapat dilihat di Gambar 6 .

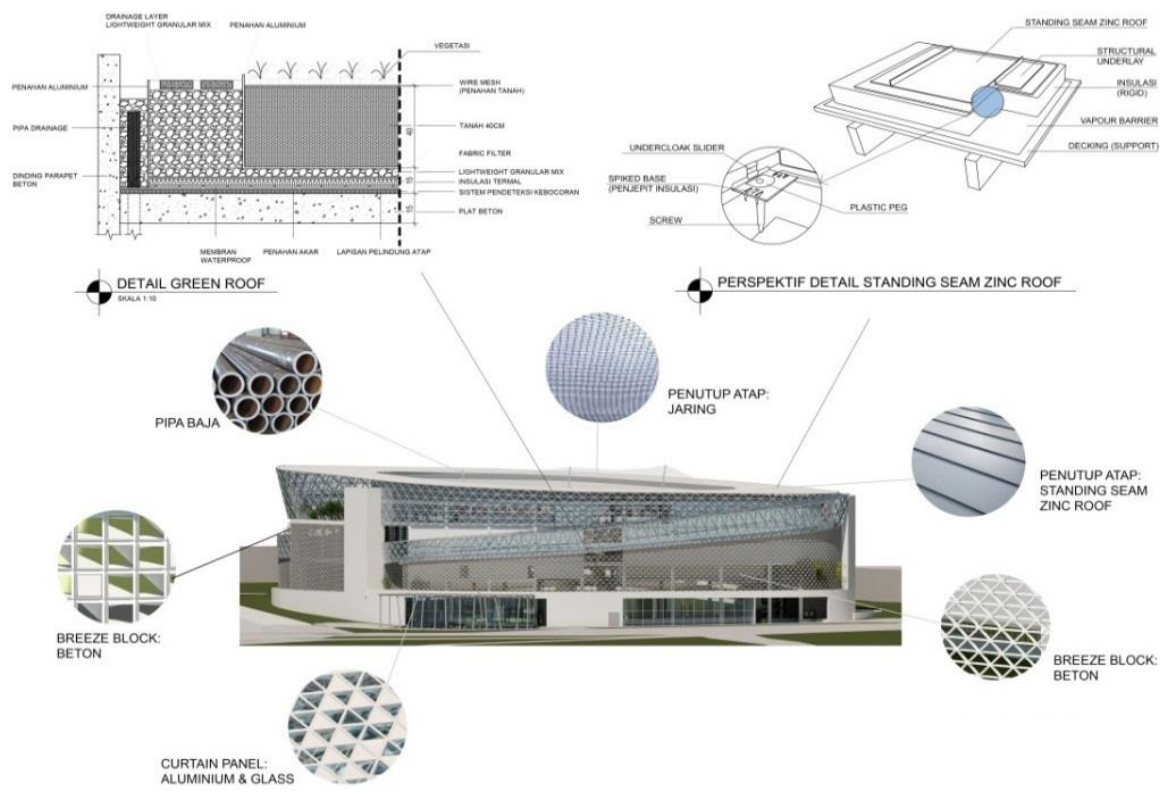

Gambar 6. Material

Sumber: Penulis, 2019 


\section{KESIMPULAN DAN SARAN}

Mediate space adalah sebuah ruang perantara bagi manusia dan khususnya hewan peliharaan. Bangunan ini merupakan sebuah wadah yang membantu untuk memberikan dampak positif bagi kehidupan manusia dan hewan. Masyarakat luas akan diperkenalkan kepada metode Animal Assited Therapy dan akan disadarkan mengenai Animal Welfare. Kedua user bangunan akan diuntungkan. Manusia akan dapat menjalin hubungan yang lebih sehat dan kesehatan mental yang lebih baik secara keseluruhan. Hewan-hewan liar dan yang diabuse dapat mendapatkan sebuah kesempatan hidup yang baru dimana mereka akan dirawat, dihargai, dicintai dan diperhatikan.

\section{REFERENSI}

Armstrong, T. (2008). The Human Odyssey: Navigating the Twelve Stages of Life. New York: Sterling.

Awan, N., Schneider, T., \& Till, J. (2011). Spatial agency: Other ways of doing architecture . Abingdon, Oxon [England]: Routledge.

A suitable environment for dogs . Retrieved July 4th, 2019, from

https://www.rspca.org.uk/adviceandwelfare/pets/dogs/environment

Bergman, S. M., dkk. (2010). Millennials, narcissism, and social networking: What narcissists do bon social networking sites and why. Personality and Individual Differences, 50 (5), 706711.

http://dx.doi.org/10.1016/j.paid.2010.12.022

Blazina, C., Boyraz, G., \& Shen-Miller, D. S. (Eds) (2013). The Psychology of theHuman-Animal Bond: A Resource for Clinicians and Researchers . New York: Springer.

Dimock, Michael. (2019). Defining generations: Where Millennials end and Generation Z begins. Retrieved July 4th, 2019, from http://www.pewresearch.org/facttank/2019/01/17/where-millennials-end-and-generation-z-begins/

Erikson, Erik H. (1994). Identity and the Life Cycle . United States of America: W.W. Norton \& Company.

Horses: the need for a suitable environment. Retrieved July 5th, 2019, from https://www.nidirect.gov.uk/articles/horses-need-suitable-environment

$\mathrm{Ng}$, E. S. W. \& Johnson, J. M. (2015). Millennials: who are they, how are they different, and why should we care? The Multi-generational and Aging Workforce (pp 121-137)

Sweeney, R. (2006). Millennial Behaviors \& Demographics, 1-10. Retrieved from http://unbtls.ca/teachingtips/pdfs/sew/Millennial-Behaviors.pdf

Teh,S.W. Lianto, F. \& Trisno, R. (2018). The impact of column and beam construction system to interior design layout according to fengshui. International Journal of Covil Engineering and Technology (IJCIET, 09(13), 1822-1827

Urichuk, L. J., Anderson, D., \& Chimo Project. (2003). Improving mental health through animalassisted therapy. Edmonton, Alberta: Chimo Project .

Verga, M \& Michelazzi, M .(2009). Companion animal welfare and possible implications on the human-pet relationship .Italian Journal of Animal Science, 8(1), 231-240, DOI:10.4081/ijas.2009.s1.231

What is a suitable environment for cats ? Retrieved July 5th,From

https://www.rspca.org.uk/adviceandwelfare/pets/cats/environment

What is a suitable environment for pet rabbits? Retrieved July 5th, 2019, from

https://www.rspca.org.uk/adviceandwelfare/pets/rabbits/environment

Yap, J., Stories and Lessons on Feng Shui, Kuala Lumpur: Mastery Academy of Chinese Metaphysics Sdn. Bhd, 2004.

Zilcha-Mano, S., Mikulincer,M. \& Shaver, P. R.(2011). An attachment perspective on humanpet relationships: Conceptualization and assessment of pet attachment orientations. 
Journal of Research in Personality. Journal of Research in personality, 45(4) , 345-357, DOI: 10.1016/j.jrp.2011.04.001 